\title{
Criança com varicela: conhecimento e práticas de profissionais da educação infantil e da saúde
}

\section{Children with chickenpox: knowledge and practices of health and child education professionals}

\author{
Tabatha de Freitas Moreira Santos ${ }^{1}$, Flávia Lopes Gabani ${ }^{2}$, Rosangela Aparecida Pimenta \\ Ferrari $^{3}$, Mauren Teresa Grubisich Mendes Tacla ${ }^{4}$
}

\begin{abstract}
Resumo
Trata-se de pesquisa descritiva, quantitativa e transversal, para analisar o conhecimento acerca da varicela entre profissionais das áreas da educação infantil e da saúde, antes da participação em oficinas de educação em saúde. Os dados foram coletados por meio de questionários autoaplicados e processados no programa Epi Info ${ }^{\circledR}$, considerando-se para análise estatística nível de significância de 5\%. Participaram 92 profissionais de oito Centros de Educação Infantil e duas Unidades de Saúde da Família de Londrina (PR). Mais de $52,0 \%$ dos profissionais da saúde e $74,0 \%$ da educação desconheciam a doença. Para $76,0 \%$ dos profissionais da educação e $38,1 \%$ dos da saúde a varicela não apresenta complicações, e a etiologia viral reportada foi de $75,0 \%$ e $50,0 \%$, respectivamente. A varicela ainda é uma doença prevenível, pouco conhecida entre ambas as categorias profissionais, que emerge para a adequada assistência e redução da transmissibilidade mediante programas de educação em saúde, além da imunização.
\end{abstract}

Palavras chave: Enfermagem. Varicela. Assistência Integral à Saúde. Educação em Saúde. Creche.

\begin{abstract}
This is a descriptive, quantitative and cross-sectional study to analyze the knowledge of child education and health professionals about chickenpox, previous to a health education workshop they attended. Data were collected through self-completion questionnaires and analyzed using the Epi Info ${ }^{\circledR}$ software, considering 5\% statistically significant level. There were 92 participants from eight Child Day Care Centers and two Basic Health Care Centers in Londrina - PR. More than $52.0 \%$ of health professionals and $74.0 \%$ of child education professionals didn't know the disease. To $76.0 \%$ of child education professionals and $38.1 \%$ of health professionals, chickenpox does not present complications and its viral etiology was reported in $75.0 \%$ and $50.0 \%$ of professionals, respectively. Chickenpox is a disease that can still be prevented, little known among these two categories of professionals, and requires adequate assistance and reductions of transmissibility through health education programs, besides immunization.
\end{abstract} Keyword: Nursing. Chickenpox. Comprehensive health care. Health education. Child day care centers.

\footnotetext{
${ }^{1}$ Especialização em Enfermagem em Saúde da Criança pela Universidade Estadual de Londrina.

2 Doutora em Saúde Coletiva pela Universidade Estadual de Londrina. Departamento de Enfermagem, Hospital Universitário da Universidade Estadual de Londrina; Londrina, Paraná, Brasil. E-mail: lopesgabani@gmail.com

${ }_{3}^{3}$ Doutorado em Enfermagem pela Universidade de São Paulo. Departamento de Enfermagem, Universidade Estadual de Londrina; Londrina, Paraná, Brasil.

${ }^{4}$ Doutorado em Enfermagem em Saúde Pública pela Universidade de São Paulo. Departamento de Enfermagem, Universidade Estadual de Londrina; Londrina, Paraná, Brasil.
} 


\section{Introdução}

A varicela, também conhecida como catapora, é uma doença que vem sofrendo importante mudança em seu contexto atual (ANJOS et al., 2009; PELLINI, 2006). A simples patologia benigna e considerada antigamente característica da infância passou também a acometer cada vez mais adultos jovens e adolescentes, resultando em complicações graves que podem gerar sequelas e mortes (ANJOS et al., 2009; YAMAGUTI; SANTOS; LIMA, 2008).

Apesar da baixa mortalidade, a morbidade pode ser alta e apresentar distribuição universal, caracterizandose como um problema de saúde pública (ANJOS et al., 2009). Sua manifestação se dá por exantema máculo-papular de forma centrípeta, infecciosa e altamente contagiosa, tendo como único hospedeiro o homem, o qual contrai a varicela por meio de gotículas nasofaríngeas, aerosóis ou contato direto e indireto com pessoas contaminadas pelo vírus Varicela Zoster (VVZ) (BRASIL, 2010).

Os casos de varicela podem aparecer durante todo o ano, porém a maior incidência ocorre no fim do inverno até a primavera, agosto a novembro, com picos nos meses de setembro e outubro (CARVALHO et al., 2007). Normalmente atinge pessoas sadias, nas quais nada causa além dos sinais e sintomas esperados. Entretanto, quando o acometimento se dá em pessoas imunocomprometidas (neoplasias, transplantados etc.), neonatos, idosos e gestantes, pode apresentar letalidade de até 30,0\% (SANTO, 2007).

No Brasil, acredita-se que a realidade seja subnotificada, já que essa patologia não faz parte da relação de doenças de notificação compulsória, a qual é realizada somente em casos de surto epidêmico (CARVALHO et al., 2007; SANTO, 2007).

Os Centros de Educação Infantil (CEI) são considerados locais que buscam favorecer $\mathrm{o}$ crescimento e desenvolvimento das crianças de zero a cinco anos, entretanto, estudos demonstram que também podem apresentar riscos à saúde devido à aglomeração de pessoas, aumentando a probabilidade de transmissão de doenças infectocontagiosas, como a varicela (VICO; LAURENTI, 2004).

A atuação das equipes de saúde nas instituições de ensino, quando presentes, se dá de forma pontual e limitada aos momentos de campanhas de vacinação ou surtos epidêmicos (GABANI; MAEBARA; FERRARI, 2010). Isso demonstra que a parceria entre os setores saúde e educação, no que se refere à promoção da saúde e prevenção de doenças e danos entre pré-escolares, ainda é restrita frente às reais necessidades da população infantil, sendo necessário trabalho intersetorial entre unidades locais de saúde e CEI, como preconizado pela Agenda de Compromissos do Ministério da Saúde para a Saúde Integral da Criança e Redução da Mortalidade Infantil, por meio do planejamento e desenvolvimento de ações educacionais e atividades de integração (BRASIL, 2004).

Sendo assim, o presente estudo teve como objetivo analisar o conhecimento acerca da varicela entre profissionais das áreas da educação infantil e da saúde previamente à participação em oficinas de educação em saúde.

\section{Material e Método}

Trata-se de um estudo descritivo, quantitativo e transversal, realizado com profissionais da saúde e educação infantil da região Norte do município de Londrina (PR), no segundo semestre de 2011. A cidade possui 53 Unidades de Saúde da Família (USF), das quais nove encontram-se na região Norte devido à grande densidade populacional, geral e infantil, e piores condições de vida comparada às demais regiões.

A casuística foi composta por funcionários dos CEI (educadoras, cozinheiras e auxiliares da limpeza) e das USF (auxiliares e técnicos de enfermagem, enfermeiros, agentes comunitários de saúde, auxiliares de odontologia, nutricionista, psicóloga e educador físico) que atuavam, direta ou indiretamente, com crianças, independente do tempo de serviço e atuação nas instituições.

A seleção das instituições de saúde ocorreu pela presença da Residência de Enfermagem em Saúde da Criança da Universidade Estadual de Londrina (UEL), atuante na localidade desde 2006 frente ao importante contexto social já mencionado. Já os CEI foram identificados por meio da Secretaria de Educação do município.

Após autorização da Secretaria Municipal de Saúde e dos coordenadores dos CEI, realizou-se contato prévio com os diretores dos centros de educação e coordenadoras das USF para agendar dia e horário mais adequados para a participação dos profissionais na pesquisa e na oficina de educação em saúde sobre varicela.

Dessa forma, foram consideradas duas USF e oito CEI, sendo quatro da área de abrangência da USF A e quatro da USF B. O convite da pesquisa foi realizado a todos os profissionais das instituições 
selecionadas, havendo participação apenas daqueles que tinham disponibilidade no momento da aplicação do formulário e da oficina de educação.

Para obtenção dos dados utilizou-se um formulário previamente testado (pré-oficina), composto pelas seguintes variáveis: a) características sociodemográficas: sexo, idade, escolaridade, número de filhos, tempo de prestação de serviço infantil; b) experiência prévia com a varicela (pessoal e profissional), conhecimentos, dúvidas, dificuldades e manejo da doença.

A dinâmica de aplicação do formulário foi diferente entre USF e CEI. Nos CEI foi realizada apenas uma coleta com cada instituição, com a presença de todos os participantes de forma simultânea. Nas USF, a coleta foi realizada em mais de quatro momentos, pois o número de profissionais exigiu a divisão em pequenos grupos de até oito participantes. Apesar dessa diferença na aplicação, os critérios de preenchimento do formulário foram os mesmos, de caráter individual, não sendo permitida qualquer interação entre os participantes.

Após o preenchimento do formulário, realizou-se a oficina de educação em saúde com os 92 profissionais dos CEI e USF, totalizando aproximadamente 12 oficinas sobre varicela e seu manejo. Cada oficina teve duração de duas horas, sendo conduzida por meio dos princípios da pedagogia problematizadora. Foi utilizado material educativo elaborado pelos pesquisadores, em que foram abordadas as características da doença e seu manejo.

Os dados coletados foram digitados em dupla entrada e processados eletronicamente por meio do programa Epi Info ${ }^{\circledR}$. O programa Excel for Windows ${ }^{\circledR}$ viabilizou melhor aplicabilidade das variáveis e organização dos dados em tabelas e figuras. Para análise estatística utilizou-se o teste qui-quadrado e teste exato de Fisher, considerando nível de significância de $5 \%(\mathrm{p}<0,05)$.

Esta pesquisa seguiu as normas relativas à pesquisa envolvendo seres humanos da Resolução 196/96 do Conselho Nacional de Saúde, sendo aprovada pelo Comitê de Ética em Pesquisa envolvendo seres humanos da UEL, pelo parecer $n^{\circ} 105 / 2011$ de seis de junho de 2011 e CAAE nº 0084.0.268.000-11.

\section{Resultados e Discussão}

Participaram da pesquisa 92 profissionais, os quais estavam presentes no dia escolhido pelos CEI e USF para realização das oficinas. De acordo com a Tabela 1, a maioria dos profissionais das USF possuía o ensino médio completo (57,5\%), enquanto nos CEI prevaleceu o superior completo $(56,3 \% ; \mathrm{p}<0,001)$. Ao contrário dos CEI, 70,0\% dos profissionais das USF tinham filhos no momento da pesquisa $(\mathrm{p}=0,001)$. Quanto ao tempo de experiência com crianças, verificou-se que $60,4 \%$ dos entrevistados dos CEI afirmaram ter menos de 10 anos de experiência, diferente dos profissionais da saúde, em que $42,0 \%$ relataram tempo igual ou superior a 10 anos. Tanto os profissionais da saúde quanto dos CEI já presenciaram casos de varicela, com $82,0 \%$ e $69,0 \%$, respectivamente. Destaca-se, porém, que $4,8 \%$ dos profissionais da saúde não souberam dizer se já presenciaram casos dessa doença.

Como observado, grande parcela dos profissionais $(45,6 \%)$ respondeu ter filhos e a maioria deles $(76,1 \%)$ já presenciou casos de varicela. Esses resultados convergem positivamente em atividades laborativas voltadas ao público infantil, haja vista que quanto maior a experiência no domicílio, no trabalho ou em estudos sobre a temática, melhor será a apropriação do conhecimento e correto manejo da doença. Destacase, também, a importância da educação em saúde para que esses profissionais sejam capazes de substituírem a prática profissional empírica, nem sempre correta, pelo saber científico necessário à condução adequada dos casos.

Acerca dos conhecimentos sobre a varicela (Tabela 2), em alguns momentos os profissionais da USF mostraram-se mais preparados se comparados aos dos CEI, apesar de mais da metade de ambos alegarem não saber o que é varicela, 52,4\% e 74,0\%, respectivamente $(\mathrm{p}=0,031)$. Quando questionados quanto ao agente causador, verificou-se que na USF houve maior dificuldade de identificação, enquanto grande parte dos profissionais dos CEI respondeu corretamente como sendo de etiologia viral $(75,0 \%$, p $=0,001)$.

Quanto ao conhecimento sobre a época do ano de maior incidência da doença, não houve diferença estatística para ambas as categorias institucionais. Entretanto, apenas $28,0 \%$ e $38,1 \%$ dos profissionais da educação e saúde, respectivamente, responderam corretamente inverno/primavera (Tabela 2). Apesar dos profissionais das USF terem tido maior percentual de resposta correta, muitos pais deixam de procurar as unidades de saúde, dificultando a identificação dos casos da doença por esse serviço. Por outro lado, as crianças não deixam de frequentar a escola durante o momento de convalescência, facilitando a observação 
Tabela 1 - Caracterização dos profissionais dos CEI e USF segundo variáveis sociodemográficas, 2011, Londrina - PR.

\begin{tabular}{|c|c|c|c|c|c|}
\hline \multirow{3}{*}{ Variáveis } & \multicolumn{4}{|c|}{ Profissionais } & \multirow{3}{*}{ Valor de $\mathrm{p}$} \\
\hline & \multicolumn{2}{|c|}{ CEI } & \multicolumn{2}{|c|}{ USF } & \\
\hline & $\mathbf{n}$ & $\%$ & $\mathbf{n}$ & $\%$ & \\
\hline Escolaridade* & & & & & $<0,001$ \\
\hline Ensino Fundamental Incompleto & 1 & 2,1 & 2 & 5,0 & \\
\hline Ensino Médio & 11 & 22.9 & 24 & 60,0 & \\
\hline Ensino Superior & 36 & 75,0 & 14 & 35,0 & \\
\hline Possui filhos* & & & & & 0,001 \\
\hline Sim & 14 & 28,6 & 28 & 70,0 & \\
\hline Não & 35 & 71,4 & 12 & 30,0 & \\
\hline Tempo de trabalho com crianças (anos)* & & & & & 0,121 \\
\hline Menor de 1 a 4 & 16 & 33,3 & 13 & 41,9 & \\
\hline 5 a 9 & 13 & 27,1 & 5 & 16,1 & \\
\hline 10 e mais & 19 & 39,6 & 13 & 42,0 & \\
\hline Já presenciou casos de varicela & & & & & 0,335 \\
\hline $\operatorname{Sim}$ & 41 & 82,0 & 29 & 69,0 & \\
\hline Não & 8 & 16,0 & 11 & 26,2 & \\
\hline Não sabe & 1 & 2,0 & 2 & 4,8 & \\
\hline Total & 50 & 100,0 & 42 & 100,0 & \\
\hline
\end{tabular}

*Excluídos registros ignorados

Fonte: Autores

dos educadores quanto aos períodos de maior incidência da doença.

Ainda na tabela 2, os principais sinais e sintomas da varicela identificados tanto pelos educadores quanto pelos profissionais da saúde foram, respectivamente, as erupções cutâneas $34,9 \%$ e $43,6 \%$, seguidas pela febre, $27,9 \%$ e $44,9 \%$. As complicações decorrentes dessa doença geralmente são desconhecidas pelo senso comum, fato que pode ser observado em grande proporção no ambiente dos CEI $(76,0 \%$, p < 0,001), apesar de $38,1 \%$ dos profissionais de saúde também desconhecerem essa informação. Entre os profissionais dos CEI que afirmaram a possibilidade de complicações decorrentes da varicela, 50,0\% ressaltaram complicações gestacionais e 25,0\% pneumonias. Já os profissionais da saúde consideraram estas mesmas complicações em menor proporção (11,4\% cada), prevalecendo as erupções cutâneas com $26,9 \%$.

O senso comum, os aspectos culturais e as experiências vividas devem ser trabalhados quando são abordados temas de educação em saúde. Há necessidade de novas estratégias de ensino e recursos que visem valorizar o conhecimento apreendido, passível de ser moldado positivamente por meio de métodos lúdicos que atendam as necessidades do outro no próprio contexto e universo. Geralmente, essas técnicas são capazes de entreter, representando ideias e comportamentos da vida diária (RAMPASO et al., 2011).

Essa reflexão levanta discussão sobre a função do enfermeiro como educador em saúde permeando todos os cenários de atuação, inclusive os CEI. O processo de educar em saúde no ambiente escolar apenas é efetivo ao suscitar a necessidade de modificar fatores que interfiram na vida saudável dos alunos. Essas modificações ocorrem por meio de ações preventivas sob o saber já presente entre aqueles que anseiam por mais informações (NAZIMA et al., 2008).

Em relação ao conhecimento acerca das complicações da varicela, pode-se inferir que os profissionais das USF mencionaram aquelas que 
fazem parte do seu cotidiano e normalmente requerem alívio dos sinais e sintomas na atenção primária. Ao contrário, as queixas e complicações mais graves são encontradas em nível hospitalar.

Dessa forma, muitos conhecimentos adquiridos são reportados ao cotidiano prático como, por exemplo, as respostas encontradas sobre a época de incidência dos casos de varicela. Além disso, os achados desse estudo podem demonstrar que a desvalorização e o desconhecimento desse agravo tornam-se evidente quando os pais não procuram os serviços de saúde para diagnóstico e tratamento da varicela, e quando há continuidade da frequência escolar mesmo em casos ativos da doença.

Sobre os mitos e tabus que cercam o conhecimento da doença (Tabela 3), a maioria dos profissionais

Tabela 2 - Conhecimento dos profissionais dos CEI e USF acerca da varicela, 2011, Londrina - PR.

\begin{tabular}{|c|c|c|c|c|c|}
\hline \multirow{3}{*}{ Variáveis } & \multicolumn{4}{|c|}{ Profissionais } & \multirow{3}{*}{ Valor de $p$} \\
\hline & \multicolumn{2}{|c|}{ CEI } & \multicolumn{2}{|c|}{ USF } & \\
\hline & $\mathbf{n}$ & $\%$ & $\mathbf{n}$ & $\%$ & \\
\hline Sabe o que é varicela & & & & & 0,031 \\
\hline Sim & 13 & 26,0 & 20 & 47,6 & \\
\hline Não & 37 & 74,0 & 22 & 52,4 & \\
\hline Qual a etiologia da varicela* & & & & & 0,001 \\
\hline Vírus & 12 & 75,0 & 21 & 50,0 & \\
\hline Bactérias & 2 & 12,50 & - & - & \\
\hline Vírus e bactérias & 2 & 12,50 & - & - & \\
\hline Não sabe & - & - & 21 & 50,0 & \\
\hline Época do ano de maior incidência & & & & & 0,538 \\
\hline Verão/Outono & 19 & 38,0 & 12 & 28,6 & \\
\hline Inverno/Primavera & 14 & 28,0 & 16 & 38,1 & \\
\hline Todas as épocas & 1 & 2,0 & - & - & \\
\hline Não sabe & 16 & 32,0 & 14 & 33,3 & \\
\hline Quais os sinais e sintomas* & & & & & 0,009 \\
\hline Erupções cutâneas & 30 & 34,9 & 34 & 43,6 & \\
\hline Cicatrizes no corpo & 3 & 3,5 & 1 & 1,3 & \\
\hline Prurido & 14 & 16,3 & 3 & 3,8 & \\
\hline Febre & 24 & 27,9 & 35 & 44,9 & \\
\hline Dor no corpo & 2 & 2,3 & 1 & 1,3 & \\
\hline Não sabe & 13 & 15,1 & 4 & 5,1 & \\
\hline Existem complicações & & & & & 0,001 \\
\hline Sim & 12 & 24,0 & 26 & 61,9 & \\
\hline Não sabe & 38 & 76,0 & 16 & 38,1 & \\
\hline Complicações relacionadas à varicela* & & & & & 0,035 \\
\hline Na gestação (mãe e recém-nascido) & 4 & 50,0 & 3 & 11,4 & \\
\hline Pneumonia & 2 & 25,0 & 3 & 11,4 & \\
\hline Cegueira & - & - & 2 & 7,7 & \\
\hline Comprometimento cutâneo & - & - & 7 & 26,9 & \\
\hline Encefalite & - & - & 1 & 3,8 & \\
\hline Impotência masculina & 1 & 12,5 & - & - & \\
\hline Acometimento de órgãos internos & 1 & 12,5 & 1 & 3,8 & \\
\hline Outras & - & - & 9 & 35,0 & \\
\hline Total & 50 & 100,0 & 42 & 100,0 & \\
\hline
\end{tabular}

*Múltiplas respostas

Fonte: Autores 
de saúde e educadores considera a varicela como sendo benigna, respectivamente, $50,0 \%$ e $52,0 \%$, porém com possibilidade de desfecho fatal, $66,6 \%$ e $72,0 \%$. Em relação ao tratamento, $10,0 \%$ dos funcionários dos CEI acreditam que a cura ocorra sem acompanhamento médico, ressalta-se, porém, que por se tratar de uma doença infectocontagiosa de etiologia viral e autolimitada, a importância do acompanhamento médico se dá na detecção precoce e acompanhamento das complicações, além das notificações epidemiológicas. Quase totalidade dos entrevistados reconhece a necessidade de afastamento da criança e, apesar da restrita cobertura vacinal contra varicela, importante percentual dos profissionais da saúde $(66,7 \%)$ e educação $(72,0 \%)$ sabe da existência da mesma e que não é exclusiva aos adultos. Também, observou-se concordância quanto à transmissibilidade da doença. Outra característica que merece destaque é que $16,0 \%$ dos educadores e $11,9 \%$ dos profissionais das USF relataram que a varicela pode ser chamada de sarampo, e aproximadamente $16,0 \%$ dos entrevistados não reconhece a necessidade de notificação da doença.

Quanto à vacina, a maioria referiu saber de sua existência, mas sem conhecimentos específicos sobre indicações, contraindicações e esquema. Também, não souberam relatar o que caracterizaria uma das indicações, exemplo, um surto epidêmico em suas instituições.

Observou-se que a maioria dos profissionais de ambas as categorias acredita que a varicela seja benigna, informação que reforça a importância do presente estudo na busca de desmistificar a doença e apresentar os possíveis agravos, internações e óbitos que podem ser evitados por ações de promoção e prevenção em saúde. Ressalta-se, também, que trabalhos (SOCIEDADE BRASILEIRA DE IMUNIZAÇÕES, 2006; NGUYEN; JUMAAN; SEWARD, 2005) abordam consequências graves como óbitos, pneumonia, encefalite, síndrome de Guillain-Barré e síndrome da varicela congênita. Esses agravos demandam hospitalizações, as quais têm aumentado nos últimos anos em alguns estados brasileiros (BAHIA, 2012).

Os resultados apresentados sobre mitos e tabus da varicela estão diretamente relacionados ao conhecimento que os profissionais apresentaram neste trabalho. Ou seja, alguns profissionais dos CEI acreditam que a doença tem cura sem necessidade de acompanhamento médico, há profissionais que confundem varicela com sarampo, e quase totalidade dos entrevistados reconhece a necessidade de afastamento da creche. Esses achados inferem que esses profissionais encontram-se entre aqueles que não têm conhecimento sobre a patologia e seus possíveis agravos, entretanto, sabem que é transmissível e há necessidade de isolamento dos casos.

Vale destacar sobre o perfil de Londrina, que dados (LIMA, 2012) fornecidos pela Vigilância Epidemiológica, demonstram um discreto aumento na incidência de casos graves notificados, totalizando 18 em 2010, e 20 em 2011. Entre 2012 e 2013 não houve óbito notificado por varicela, e apenas um caso desenvolveu a doença durante a gestação. Ainda assim, como a notificação não é compulsória, exceto em casos de surto epidêmico, grande maioria das ocorrências passam despercebidas pela Vigilância Epidemiológica. Essa realidade desperta a necessidade de sensibilização das áreas da saúde e educação acerca da notificação da varicela, bem como, a realização de pesquisas que apontem às instâncias governamentais investimentos em ações de promoção e prevenção visando à redução de agravos.

Acerca da busca por resultados positivos da implementação da vacina, ensaios clínicos realizados em outros países como Estados Unidos da América (EUA) (NGUYEN; JUMAAN; SEWARD, 2005), e em cidades como Florianópolis (KUPEK; TRITANY, 2009), evidenciaram diminuição da incidência de varicela após esquema vacinal, o qual foi considerado protetor e seguro (SOÁREZ, 2009). Hirose et al. (2016) identificaram o impacto da vacina varicela nas taxas de internações hospitalares associadas à doença nos países que adotaram sua vacinação universal, demonstrando queda na hospitalização por essa causa. Porém, esses resultados foram obervados após período longo de imunização, dificultando comparações com estudos que analisam o impacto após pouco tempo decorrido da introdução da vacina.

As principais dúvidas apontadas pelos profissionais dos CEI e USF estão ilustradas no Gráfico 1. Entre os educadores destacaram-se, respectivamente, dúvidas quanto às complicações $(19,7 \%)$, tratamento $(18,0 \%) \mathrm{e}$ transmissão da varicela $(14,8 \%)$. Entre os profissionais das USF, as dúvidas relacionaram-se as complicações $(24,4 \%)$, transmissão $(13,5 \%)$ e etiologia $(13,5 \%)$.

As dúvidas sinalizadas foram semelhantes em ambas as categorias profissionais, demonstrando que o nível de conhecimento entre elas não difere significativamente. Dessa forma, ressalta-se a necessidade de capacitação em cadeia para efetivação das ações de saúde por meio da instrumentalização 
Tabela 3 - Mitos e Tabus dos profissionais dos CEI e USF acerca da varicela, 2011, Londrina - PR.

\begin{tabular}{|c|c|c|c|c|c|c|c|c|c|c|c|c|}
\hline \multirow{4}{*}{ Mitos e Tabus } & \multicolumn{12}{|c|}{ Profissionais } \\
\hline & \multicolumn{6}{|c|}{ CEI } & \multicolumn{6}{|c|}{ USF } \\
\hline & \multicolumn{2}{|c|}{ Verdadeiro } & \multicolumn{2}{|c|}{ Falso } & \multicolumn{2}{|c|}{ Não Sabe } & \multicolumn{2}{|c|}{ Verdadeiro } & \multicolumn{2}{|c|}{ Falso } & \multicolumn{2}{|c|}{ Não sabe } \\
\hline & $\mathbf{N}$ & $\%$ & $n$ & $\%$ & 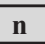 & $\%$ & $n$ & $\%$ & $\mathrm{n}$ & $\%$ & $\bar{n}$ & $\%$ \\
\hline \multicolumn{13}{|l|}{ Gravidade } \\
\hline A varicela é benigna & 26 & 52,0 & 23 & 46,0 & 1 & 2,0 & 21 & 50,0 & 17 & 40,5 & 4 & 9,5 \\
\hline Varicela pode matar & 36 & 72,0 & 9 & 18,0 & 5 & 10,0 & 28 & 66,6 & 7 & 16,7 & 7 & 16,7 \\
\hline \multicolumn{13}{|l|}{ Prevenção/Tratamento } \\
\hline $\begin{array}{l}\text { Não precisa procurar serviço de } \\
\text { saúde, pois a cura é espontânea }\end{array}$ & 5 & 10,0 & 45 & 90,0 & - & - & - & - & 38 & 90,5 & 4 & 9,5 \\
\hline Varicela tem tratamento & 47 & 94,0 & 2 & 4,0 & 1 & 2,0 & 31 & 73,8 & 5 & 11,9 & 6 & 14,3 \\
\hline $\begin{array}{l}\text { Quem tem varicela é proibido } \\
\text { frequentar creches }\end{array}$ & 50 & 100,0 & - & - & - & - & 41 & 97,6 & - & - & 1 & 2,4 \\
\hline Existe vacina para varicela & 36 & 72,0 & 12 & 24,0 & 2 & 4,0 & 28 & 66,7 & 8 & 19,0 & 6 & 14,3 \\
\hline $\begin{array}{l}\text { Somente adultos podem receber } \\
\text { vacina de varicela }\end{array}$ & 3 & 6,0 & 45 & 90,0 & 2 & 4,0 & - & - & 37 & 88,1 & 5 & 11,9 \\
\hline \multicolumn{13}{|l|}{ Transmissão } \\
\hline Varicela é transmissível & 50 & 100,0 & - & - & - & - & 39 & 92,2 & 1 & 2,4 & 2 & 4,8 \\
\hline $\begin{array}{l}\text { Deve-se desenvolver a varicela na } \\
\text { infância }\end{array}$ & 23 & 46,0 & 27 & 54,0 & - & - & 16 & 38,1 & 24 & 57,1 & 2 & 4,8 \\
\hline $\begin{array}{l}\text { Todo mundo deve desenvolver } \\
\text { varicela }\end{array}$ & 11 & 22,0 & 38 & 76,0 & 1 & 2,0 & 5 & 11,9 & 33 & 78,6 & 4 & 9,5 \\
\hline Só criança desenvolve varicela & 7 & 14,0 & 43 & 86,0 & - & - & 1 & 2,4 & 39 & 92,8 & 2 & 4,8 \\
\hline \multicolumn{13}{|l|}{ Outras características } \\
\hline A catapora é causada por vírus & 44 & 88,0 & 5 & 10,0 & 1 & 2,0 & 1 & 2,4 & 39 & 92,8 & 2 & 4,8 \\
\hline $\begin{array}{l}\text { A varicela pode ser chamada de } \\
\text { sarampo }\end{array}$ & 8 & 16,0 & 40 & 80,0 & 2 & 4,0 & 5 & 11,9 & 35 & 83,3 & 2 & 4,8 \\
\hline $\begin{array}{l}\text { Não é preciso notificar casos de } \\
\text { varicela }\end{array}$ & 2 & 4,0 & 47 & 94,0 & 1 & 2,0 & 5 & 11,9 & 35 & 83,3 & 2 & 4,8 \\
\hline
\end{tabular}

Fonte: Autores

dos agentes de saúde, para que sejam capazes de multiplicar a informação aos educadores, e estes aos pais das crianças, reforçando a prática da integralidade como um dos princípios norteadores do Sistema Único de Saúde (SUS).

Ademais, essas atividades permitem ao profissional da enfermagem identificar condições sociais e afetivas da população infantil e suas respectivas famílias, além das condições de cuidado e estimulação das crianças (FRACOLLI et al., 2011). Igualmente, garantem adequada articulação entre ações preventivas e assistenciais, capacitando a equipe de saúde para atuação em CEI na busca de melhorar não apenas a qualidade de vida da população infantil, mas também dos profissionais e da comunidade adstrita em sua área de abrangência.

Em relação ao manejo da varicela (Tabela 4), a orientação por procura médica foi destacada tanto pelos profissionais dos CEI (40,3\%), quanto das USF (40,9\%). Entretanto, importante parcela dos entrevistados $12,9 \%$ e $16,7 \%$, respectivamente, ainda não sabe o que fazer nesses casos. Houve diversidade nas dificuldades apontadas pelos dois grupos de profissionais. Entre os educadores prevaleceu a falta de compreensão e colaboração dos pais $(30,3 \%)$, seguida pela falta de conhecimento dos profissionais dos CEI (27,3\%). Já os profissionais da saúde destacaram como principais dificuldades a falta de conhecimento sobre varicela $(36,0 \%)$ e a inadequada estrutura física para isolamento dos casos $(24,0 \%)$.

Chama atenção o fato de alguns profissionais referirem não saber o que fazer com os casos de varicela, bem como apresentam este fato como dificuldade. Porém, mesmo diante de tantas dificuldades, grande parte dos profissionais orientam corretamente os pais e responsáveis pelas crianças a procurar assistência 
Gráfico 1 - Dúvidas acerca da varicela relatadas por profissionais dos CEI e USF, 2011, Londrina-PR.

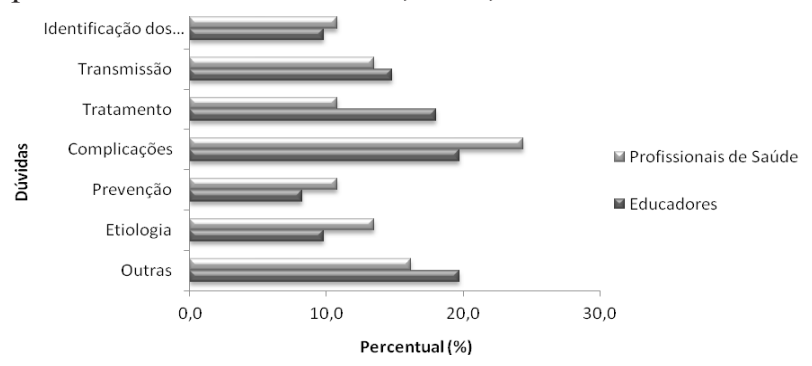

Fonte: Autores

médica, favorecendo o diagnóstico e a intervenção adequados, inclusive para identificação dos casos graves.

A falta de compreensão e colaboração dos pais pode ser compreensível ao se contextualizar a realidade socioeconômica da população do estudo, haja vista que um dia de falta laborativa pode significar um dia sem remuneração ou, até mesmo, perda do emprego. Porém, se a criança adoecer e for responsável pela contaminação de outras, o CEI pode ser fechado pela ocorrência de surto, prejudicando os demais pais e responsáveis. Diante deste cenário, a literatura refere que a varicela apresenta importante custo social e econômico, com despesas em consultas médicas, uso de medicações para alívio dos sintomas, terapêutica antiviral, hospitalizações devido às complicações e, principalmente, o ônus financeiro relacionado ao

Tabela 4 - Manejo acerca da varicela por profissionais dos CEI e USF, 2011, Londrina - PR.

\begin{tabular}{lcccc}
\hline \multirow{2}{*}{ Variáveis } & \multicolumn{5}{c}{ Profissionais } \\
\cline { 2 - 5 } & \multicolumn{3}{c}{ CEI } & \multicolumn{2}{c}{ USF } \\
\cline { 2 - 5 } & N & $\%$ & $\mathbf{n}$ & $\%$ \\
\hline Condutas no manejo da varicela* & & & & \\
$\quad$ Isolamento/Afastamento & 9 & 14,5 & 14 & 21,2 \\
Acompanhamento profissional & 25 & 40,3 & 27 & 40,9 \\
Orientação familiar & 20 & 32,3 & 14 & 21,2 \\
Não sabe & 8 & 12,9 & 11 & 16,7 \\
Dificuldades no manejo da varicela & & & & \\
Não tem & 5 & 15,1 & 3 & 12,0 \\
Nunca presenciou um caso & 2 & 6,1 & - & - \\
Estrutura física (isolamento) & 2 & 6,1 & 6 & 24,0 \\
Compreensão/Colaboração dos pais & 10 & 30,3 & - & - \\
Falta de conhecimento dos profissionais & 9 & 27,3 & 9 & 36,0 \\
Falta de informações dos pais & 2 & 6,1 & 2 & 8,0 \\
Outras: & 3 & 9,0 & 5 & 20,0 \\
\hline
\end{tabular}

*Múltiplas respostas

Fonte: Autores absenteísmo dos responsáveis pela criança (ANJOS et al., 2009; CARVALHO et al., 2007).

Dessa forma, a presente pesquisa também procurou minimizar essas ocorrências, aprimorando o conhecimento de ambas as categorias profissionais sobre a varicela e seu contexto multidimensional, potencializando a articulação entre os diferentes atores sociais e estreitando o vínculo entre educadores de CEI e equipes de saúde das USF.

\section{Conclusão}

Ao analisar os dados obtidos, verificou-se que a bagagem de conhecimento entre educadores e profissionais de saúde foi semelhante, ainda que os profissionais das USF tenham apresentado menos dificuldades na realização do pré-teste. Salienta-se que preocupante percentagem de ambas as categorias profissionais alegaram não saber o que é varicela e quais as possíveis complicações, apresentam cotidianamente dificuldades na identificação de casos, e ainda há crenças e mitos que representam perigo à saúde da população infantil.

Os achados desde estudo reforçam a necessidade de ações educativas de capacitação dessa população para lidar com o tema, considerando o importante papel que possuem no crescimento e desenvolvimento saudável das crianças sob sua responsabilidade.

Em instâncias superiores, a varicela vem ganhando magnitude e interesse das autoridades de saúde por se tratar de doença imunoprevinível, capaz de incrementar a morbimortalidade não apenas das crianças, mas também dos adultos. Destarte, tratase de um problema de saúde pública que deve ser trabalhado embasado na integralidade das ações de saúde por toda equipe envolvida, sendo o profissional enfermeiro importante articulador desse processo. Porém, a adequada assistência requer mobilização dos níveis de atenção envolvidos para formação de redes de apoio intersetoriais, ou seja, um desafio a ser alcançado.

Importa ressaltar que há necessidade de mais estudos para vislumbramento da temática, pois como não se trata de doença de notificação compulsória, deve-se mostrar os aspectos culturais e técnicos que permeiam o tema de outras formas. Com a introdução da tetravalente viral no calendário nacional de imunizações em 2013, a qual contém a vacina contra varicela, novas pesquisas serão necessárias para avaliação do impacto epidemiológico na saúde infantil e população em geral. 


\section{Referências}

ANJOS, K. S.; FERREIRA, M. M. E.; ARRUDA, M. C.; RAMOS, K. S.; MAGALHÃES, A. P. R. Caracterização epidemiológica dos casos de varicela em pacientes internados em um hospital universitário da cidade do Recife. Revista Brasileira de Epidemiologia, São Paulo, v. 12, n. 4, p. 523532, 2009.

BAHIA. Secretaria de Saúde. Subcoordenadoria de Vigilância Sanitária. Diretoria de Vigilâncias Epidemiológica. Boletim epidemiológico da Varicela. Salvador, 2012. v. 1.

BRASIL. Ministério da Saúde. Secretaria de Atenção à Saúde. Departamento de Ações Programáticas Estratégicas. Agenda de compromissos para a saúde integral da criança e redução da mortalidade infantil. Brasília, 2004.

BRASIL. Ministério da Saúde. Secretaria de Vigilância em Saúde. Departamento de Vigilância Epidemiologia. Doenças infecciosas e parasitárias: guia de bolso. Brasília, 2010.

CARVALHO, J. Z. M.; RODRIGUES, T. R.; AZZI, T. T.; BURIHAN, P. C. P. R. Varicella outbreak in the capela do Socorro, 2005. Revista de Medicina, São Paulo, v. 86, n. 3, p. 148-154, 2007.

FRACOLLI, L. A.; ZOBOLI, E. L. P.; GRANJA, G. F.; ERME, R. C. Conceito e prática da integralidade na atenção básica: a percepção das enfermeiras. Revista da Escola de Enfermagem da USP, São Paulo, v. 45, n. 5, p. 1135-1141, 2011.

GABANI, F. L.; MAEBARA, C. M. L.; FERRARI, R. A. P. Pediculose nos centros de educação infantil. Escola Anna Nery Revista de Enfermagem, Rio de Janeiro, v. 14, n. 2, p. 309-317, 2010.

HIROSE, M.; GILIO, A. E.; FERRONATO, A. E.; RAGAZZI, S. L. B. Impacto da vacina varicela nas taxas de internações relacionadas à varicela: revisão de dados mundiais. Revista Paulista de Pediatria, São Paulo, v. 34, n. 3, p. 359-366, 2016.

KUPEK, E.; TRITANY, E. F. Impact of vaccination against varicella on the reduction of the disease incidence in children and adolescents from Florianópolis, Brazil. Jornal de Pediatria, Rio de Janeiro, v. 85, n. 4, p. 365-368, 2009.

LIMA, Lucia Helena. Banco de dados: casos graves de Varicela no Município de Londrina. [mensagem pessoal]. Mensagem recebida por <luciahelenalima@gmail.com>em 10 ago. 2012.
NAZIMA, T. J.; CODO, C. R. B.; PAES, I. A. D. C.; BASSINELLO, G. A. H. Orientação em saúde por meio do teatro: relato de experiência. Revista Gaúcha de Enfermagem, Porto Alegre, v. 29, n. 1, p. 147-151, 2008.

NGUYEN, H. Q.; JUMAAN, A. O.; SEWARD, J. F. Decline in mortality due to varicella after implementation of varicella vaccination in the United States. New England Journal of Medicine, Boston, v. 352, n. 5, p. 450-458, 2005.

PELLINI, A. C. G. Estudo de fatores preditores de gravidade e óbito por varicela em residentes da Região Metropolitana da Grande São Paulo, (SP), 2003. 2006. Dissertação (Mestrado) - Faculdade de Saúde Pública, Universidade de São Paulo, São Paulo, 2006.

RAMPASO, D. A. L.; DORIAL, M. A. G.; OLIVEIRAL, M. C. M.; SILVA, G. T. R. Teatro de fantoche como estratégia de ensino: relato da vivência. Revista Brasileira de Enfermagem, Brasília, v. 64, n. 4, p. 783-785, 2011.

SANTO, A. H. Tendência da mortalidade relacionada à varicela no Estado de São Paulo, Brasil, 1985 a 2004: estudo usando causas múltiplas de morte. Revista Panamericana de Salud Pública, Rio de Janeiro, v. 22, n. 2, p. 132-140, 2007.

SOÁREZ, P. C. Uso de modelos de análise de decisão nos programas de vacinação contra a varicela. 2009. Tese (Doutorado) - Faculdade de Medicina da Universidade de São Paulo, São Paulo, 2009.

SOCIEDADE BRASILEIRA DE IMUNIZAÇÕES. Informe Varicela, ano 1, n. 5, set. 2006.

VICO, E. S. R.; LAURENTI, R. Mortalidade de crianças usuárias de creches no Município de São Paulo. Revista de Saúde Pública, Rio de Janeiro, v. 38, n. 1, p. 38-44, 2004.

YAMAGUTI, H. Y.; SANTOS, A. C. J.; LIMA, G. Z. Conhecimentos sobre Varicela de alunos ingressantes em cursos da área de saúde na Universidade Estadual de Londrina e verificação da presença de cicatrizes da doença. Semina: Ciências Biológicas e da Saúde, Londrina, v. 29, n. 1, p. 3-8, 2008. 
de Freitas Moreira Santos, T. et al. 